\title{
The Evolution of Journal of Korean Neurosurgical Society from 2017 to 2020 : The Beginning of a Great Development
}

\author{
Moonyoung Chung, ${ }^{1}$ Bum-Tae Kim ${ }^{1,2}$ \\ Department of Neurosurgery,' Soonchunhyang University Bucheon Hospital, Bucheon, Korea \\ Former Editor-in-Chief, Journal of Korean Neurosurgical Society
}

Every researcher wants their research to gain more recognition, and this desire is achieved by publishing their article in a journal with higher impact. It is very important to get researchers interested in the Journal of Korean Neurosurgical Society (JKNS). Therefore, the first goal was to promote the publication of papers in our journal. To do this, a table of contents was sent out, and the citation ranking was announced every 2 months. Several efforts have been made to publish good papers. Foreign speakers, who were invited to a conference hosted by the Korean Neurosurgical Society were contacted and politely requested to write a paper addressing their recent research. Domestic and international researchers highly renowned in their fields were also contacted to submit their novel works to our journal. The journal impact factor of our journal has continued to rise for the last 3 years and reached 1.376 in 2019. It can be said that the JKNS is now competitive with other international neurosurgery journals. These achievements were not due to the efforts of the editorial boards alone. This was because our society members have submitted very good papers, and because many of our members have cited the papers published in our journal. We believe that this will continue in the future. The next step of evolution of the JKNS has begun, and this is the beginning of another great development.

Key Words : Journal of Korean Neurosurgical Society · Publications · Journal impact factor.

\section{INTRODUCTION}

The Korean Neurosurgical Society (KNS) was established in 1961 and is composed of more than 3000 neurosurgeons in South Korea, which is by no means a small number ${ }^{6}$. The Journal of Korean Neurosurgical Society (JKNS) is the official journal of the KNS, and the principal purpose of the JKNS is to provide a large number of KNS members an opportunity to publish their scientific research. However, JKNS has been an important space for sharing scientific and clinical work not only for the members of our society but also for international authorships of our journal.

The impact factor (IF) calculated by Clarivate Analytics Co. is accepted to be one of the most prestigious scores for assessing the quality of an international scientific journal ${ }^{7)}$. The JKNS has become internationally recognized after being listed in the Scientific Citation Index Expanded in 2008. However, the IF of the JKNS had been stagnant for many years ${ }^{6}$. There had been many problems that contributed to this situation, which were difficult to overcome, including a lack of aware-

- Received : April 14, 2021 •Revised : April 25, 2021 •Accepted : April 25, 2021

- Address for reprints : Bum-Tae Kim

Department of Neurosurgery, Soonchunhyang University Bucheon Hospital, 170 Jomaru-ro, Bucheon 14584, Korea

Tel : +82-32-621-5289, Fax : +82-32-621-5107, E-mail : bumtkim@gmail.com, ORCID : https://orcid.org/0000-0003-2646-8165

This is an Open Access article distributed under the terms of the Creative Commons Attribution Non-Commercial License (http://creativecommons.org/licenses/by-nc/4.0) which permits unrestricted non-commercial use, distribution, and reproduction in any medium, provided the original work is properly cited. 
ness of publishing ethics, the domestic nature of our journal, and indifferences among the members of the JKNS. Therefore, the most important mission of the former editor-in-chief of JKNS was to increase its IF.

\section{EFFORTS FOR INCREASING THE IF}

Three components were needed to make the JKNS a highquality journal (Fig. 1). First, scientifically interesting research papers should be continuously submitted to $J K N S^{2)}$. Second, good peer who could make good reviews were required regardless of the quality of the paper submitted. Third, editors were required to continue their efforts to comply with the international ethical and scientific standards. The combination of these three components might increase the influence of the JKNS in the international medical science field, leading to a higher IF. This idea was shown through the workshop at the 58th Annual Meeting of the KNS on October 11, 2018 (Fig. 2).

\section{Enhancing scientific interests}

The first effort was to make researchers interested in the JKNS. We started to send out a table of contents of a new issue as well as a list of top cited articles to our society members and past-authors, every 2 months (Fig. 3). This email showed that the editorial board is working continuously to improve reputation of the journal and to reach out to potential authors of JKNS. Furthermore, the authors will be delighted that their papers published on JKNS are promoted and that its value was recognized.

In order to arouse the interest of general readership of neu-

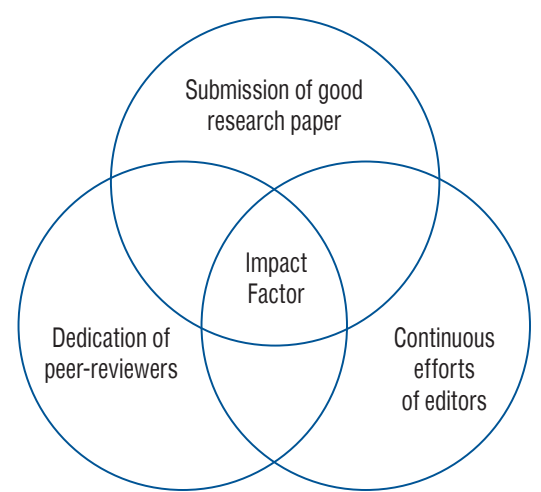

Fig. 1. Three components are required to build a high-quality journal. The combination of these factors allows for a scientific journal to gain more recognition, which is presented as an impact factor. rosurgery, review articles with up-to-date perspectives were politely requested. The members of the editorial board invited internationally renowned authors to write review papers on subjects of their scientific interest. Since 2018, we have received more than 10 review papers, all of which have been published through a careful peer review process. In addition, excellent papers published by authors were awarded as "influential articles" ${ }^{\prime 5)}$. All of these efforts motivated the authors to submit their papers to the JKNS.

\section{Early online publication}

It was also important to increase publicity opportunities for articles published in our journal ${ }^{3)}$. Increasing publicity opportunities meant that the accepted articles would get published on the web as quickly as possible, which would lead to early epublication. The authors were asked to make a quick final correction so that the accepted manuscript could be released

EDITING COMMITTEE THURSDAY, OCTOBER 11, 2018

\section{$09: 00 \sim 12: 00$}

Hangang (Annex 1F)

\section{Practical Workshop for the Quality Improvement of JKNS}

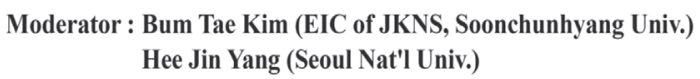

편집-01 Pitfalls that Editors and Reviewers Must Consider when Evaluating Academic Papers

Sun Young Lee (Konkuk Univ.)

편집-02 How to Increase the Influence of JKNS in the Field of International Medical Science

Jae-Weon Kim (EIC of Journal of Gynecologic Oncology)

편집-03 Publishing Ethics that Authors of the Medical Journal Must Know

Dong Soo Han

(Chairman of Publication Ethics, Kor. Association of Med. J. Editors)

편집-04 How to Use the JKNS Website?

Youn Sang Cho (Product Manager, M2community)

Fig. 2. Program lists of the practical workshop during the 58th Annual meeting of the Korean Neurosurgical Society on Oct. 11, 2018. This workshop program embodied how we used strategic thinking to improve the quality of the Journal of Korean Neurosurgical Society (JKNS). 
as an e-publication as soon as possible. There was also a problem with the duration of completion of the review. In the second half of 2017, the average time taken from submission to the acceptance of an article was approximately 100 days. To reduce the duration, we urged the reviewers for a faster review. Furthermore, to praise reviewers for their dedication, an award for the best reviewer was given. Although this award did not provide any economic incentives, it acknowledged the reviewer's contribution to the development of the JKNS. Consequently, it was possible to shorten the average time of publication to 63 days by the end of 2019 .

\section{EXPERIENCES OF ETHICAL ISSUES}

Building higher ethical standards for the JKNS is an important task. There have been several ethical issues over the past 3 years, including authorship, data plagiarism, duplicated submission, lack of approval from an Institutional Review Board (IRB), lack of informed consent, and preprint requirements.

\section{Authorships}

In one case, a researcher who was not on the author list of an article that had already been published claimed that he had contributed to this article but was not on the author list. The editorial committee inquired with the corresponding author to confirm if the claimer's argument was correct. The corresponding author confirmed this fact, and therefore, the paper was withdrawn with agreement between the authors and the claimer. In another case, new authors were requested to be added to the review paper while in others, some authors listed in the submitted paper were excluded. According to the authors' instructions, the authors cannot modify or add to the manuscripts that have already been under review. The editorial committee decided to mandate to specify "authors contributions" and "ORCID" at the end of the text to avoid recurrence of these events.

\section{Plagiarism issues}

An argument occurred about a photo cited in one paper that was taken from another researcher's work without permission. This happened because the author was not concerned

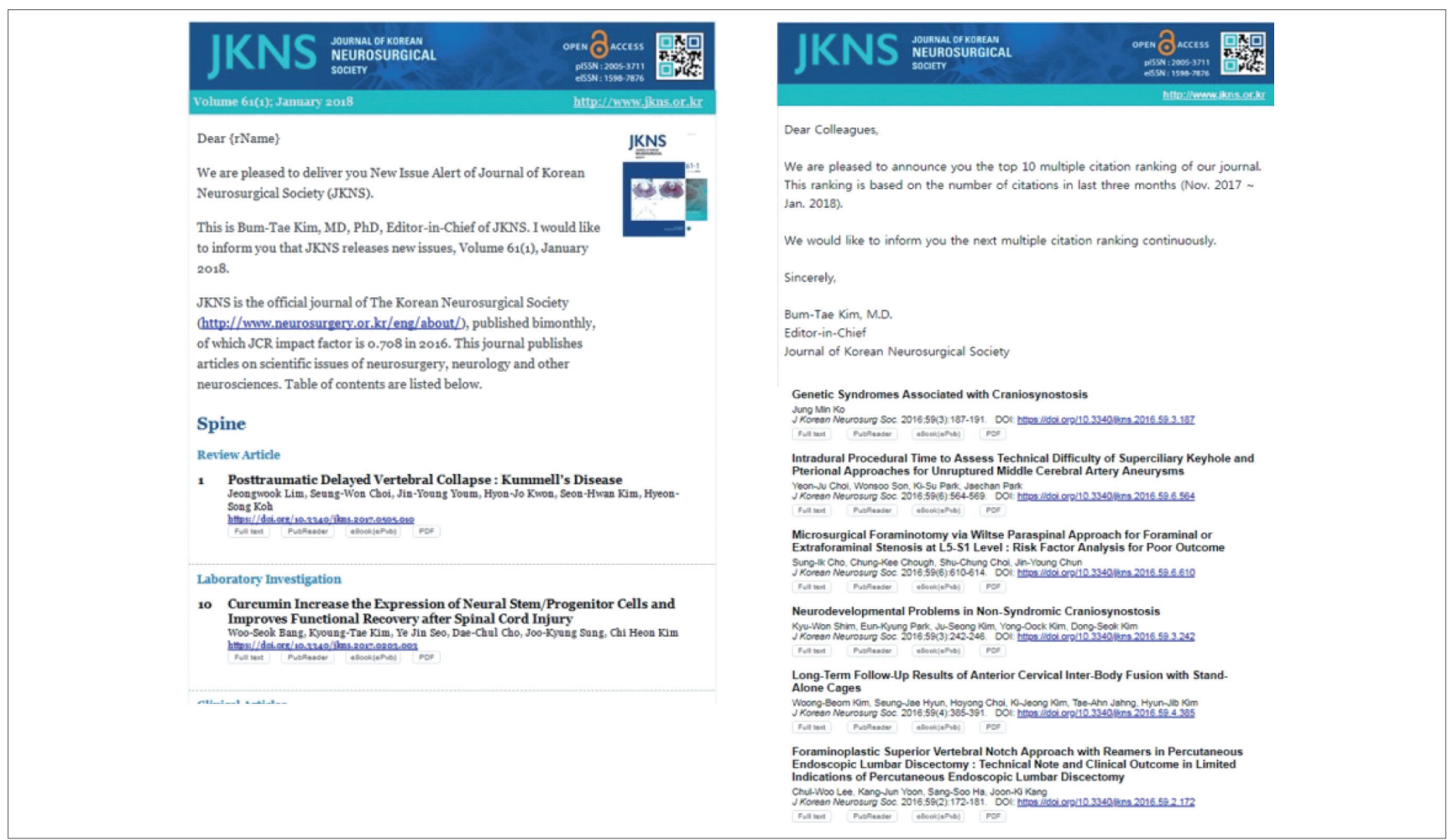

Fig. 3. Mailing forms of the "table of contents" and "citation ranking" of the Journal of Korean Neurosurgical Society (JKNS). The promotion of current JKNS news was the most basic step that the editorial board could take to evolve the journal. 
about obtaining the original photo. Thus, the author consulted with the copyright-holder of the photo. The problem was resolved by specifying the source of the original photo through the erratum after the acquisition of permission. An issue regarding redundant publications is discussed as follows : in the review process of one submitted article, the editor found another paper published in a different journal that contained the same method and partially duplicated results, written by the same authors. However, the author did not cite or specify the source of the paper, and for this reason, this paper was rejected in the review process.

\section{Other problems}

In some cases, submitted clinical studies were found not to have IRB approval during the review process. After notifying the author that acquisition of the IRB is required for clinical studies, the studies were rejected. In some cases, patient consent was not received for photos of suspected personal information leakage. The editorial committee was consulted for each of those cases, and the committee asked the author to rectify the issue when the photos in the manuscript could violate patient rights. There were many ways to solve the issue, that is, to receive consent from the patient, to exclude photos containing the patient's physical characteristics from the paper, and to replace the photos with illustrations.

Problems with the preprint have emerged recently. As a way to share new research results more quickly, there are cases in which papers are preprinted before they have been peer-reviewed. In general, preprints are not regarded as redundant publications, so the editorial committee of the JKNS has also made rules for this, wherein the authors are required to indicate in their manuscript whether a version of a preprint exists.

\section{CLOSING REMARKS}

Valuable scientific works should be widely shared because scientific knowledge that is not shared and evaluated is nothing more than dead knowledge. All researchers want their study to gain more recognition and be published in a highlyrated journal $^{1)}$. The higher the IF the JKNS acquires, the more researchers would like to publish their research through $J K N S$. In terms of this aspect, the recent remarkable rise in the IF of the JKNS is a notable achievement of our society (Fig. 4). In 2019 , the IF of the JKNS was rated as $1.376^{4)}$. This achievement was achieved by the efforts made by the JKNS to make it a high-quality journal that meets international standards in ethics and science ${ }^{8)}$.

There has been some debate as to whether the IF of JKNS does not fit the KNS's stature. Many KNS members speculated that it was because the word "Korea" was included in the title of the journal, which gives the impression that is only for domestic readership. Therefore, there were some efforts to exclude the word "Korea" from the title. However, it is also true that our journal must reflect the regional academic interests of South Korea even though it is an international journal. Since our journal was created in response to the needs of the members of the KNS, changing the title would mean that we

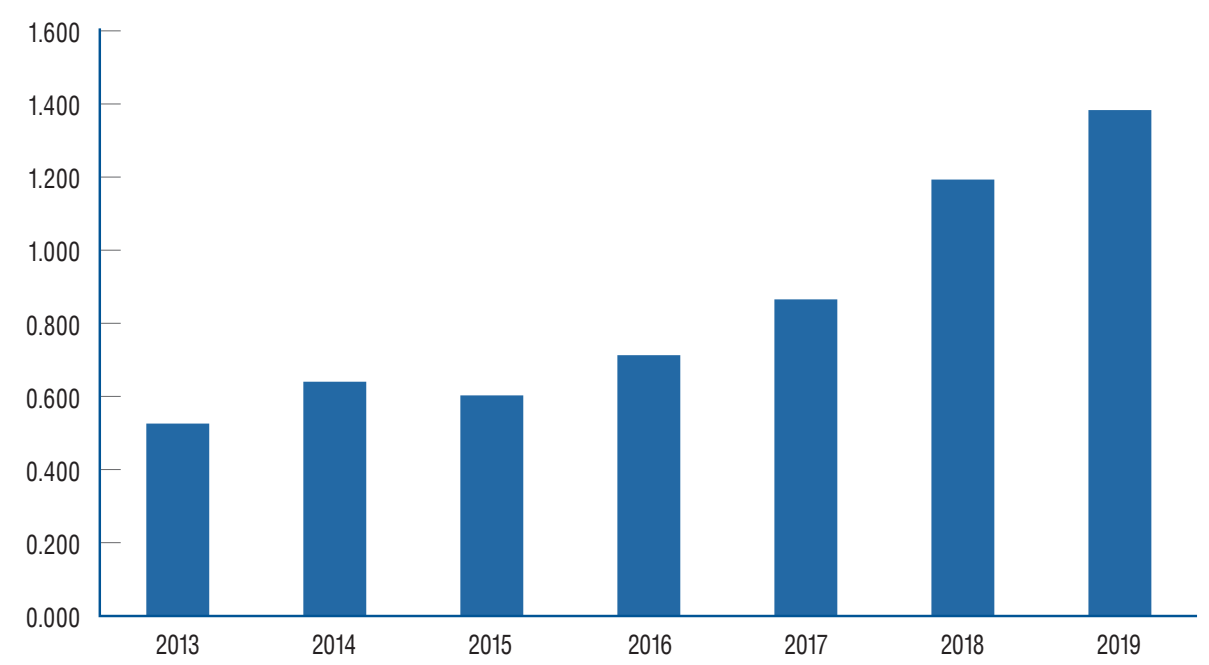

Fig. 4. The impact factor of the JKNS has continuously increased over the last 5 years. In 2019, the impact factor of the JKNS was rated as 1.376. 
would have to deal with international interests completely beyond regional interests. However, this could prevent members of the KNS from publishing their own scientific works. For this reason, the argument for changing the name is no longer discussed. Our journals must consistently meet high scientific standards and adhere to high ethical standards. Although it is not easy to do this, these efforts will eventually provide a better research environment for the KNS members. Consequently, the JKNS will enable researchers to contribute to the academic development of neurosurgery. The next step of evolution of JKNS has begun, and this is the beginning of another great progress.

\section{CONFLICTS OF INTEREST}

Moonyoung Chung has been editorial board of JKNS since Novemebr 2017 and Bum-Tae Kim has been editorial board of JKNS since Novemebr 2014. They were not involved in the review process of this article. No potential conflict of interest relevant to this article was reported.

\section{INFORMED CONSENT}

This type of study does not require informed consent.

\section{AUTHOR CONTRIBUTIONS}

\section{Conceptualization : BTK}

Data curation : MC, BTK

Funding acquisition : BTK

Methodology: MC, BTK

Project administration : BTK

\author{
Writing - original draft : MC, BTK \\ Writing - review \& editing : MC, BTK
}

\section{ORCID}

Moonyoung Chung https://orcid.org/0000-0003-4733-6321

Bum-Tae Kim https://orcid.org/0000-0003-2646-8165

\section{- Acknowledgements}

This work was supported by the Soonchunhyang University Research Fund.

\section{References}

1. Bornmann L, Pudovkin Al : The journal impact factor should not be discarded. J Korean Med Sci 32 : 180-182, 2017

2. Chung M, Kim BT : Editorial statistics and best reviewers award 2018 for Journal of Korean Neurosurgical Society. J Korean Neurosurg Soc 62 : 1-2, 2019

3. Chung M, Park CK, Yang HJ : Editorial statistics and best reviewer awards 2020 for the Journal of Korean Neurosurgical Society. J Korean Neurosurg Soc 64 : 1-3, 2021

4. Clarivate : Journal citation reports. 2019 journal impact factor. Boston : Clarivate Analytics, 2020

5. Im SB, Chung M, Kim BT : The influential articles and title words in the Journal of Korean Neurological Society publications between the years 2016 to 2018. J Korean Neurosurg Soc 63 : 1-3, 2020

6. Kim BT, Chung $M$ : Evolution of quality improvement for the Journal of Korean Neurosurgical Society. J Korean Neurosurg Soc 61 : 425426, 2018

7. Sinowatz $\mathrm{F}$ : The impact of the impact factor. Anat Histol Embryol 45 : 159-160, 2016

8. Yang HJ : Journal of Korean Neurosurgical Society from 2001 to 2006, the pivotal period of transition and preparation for making great stride. J Korean Neurosurg Soc 62 : 131-135, 2019 